\section{rev Psi}

Revista de Psicología (UNLP)

https://revistas.unlp.edu.ar/revpsi

\title{
Lo ultramoderno y lo perverso arcaico. Persistencia de abusos y maltratos en las organizaciones familiares
}

\author{
Jorge Carlos Garaventa' \\ Correspondencia \\ jorgegaraventa@hotmail.com.ar \\ Filiaciones institucionales \\ ${ }^{1}$ Federación de Psicólogos de la República \\ Argentina (FEPRA) (Argentina)
}

\section{Resumen}

Históricamente las organizaciones familiares han sido relacionadas con la génesis de las violencias y los abusos contra la niñez bajo el disfraz o el escudo de la educación. Se ha pensado que las formas rígidas en la estructuración de las mismas serían en parte facilitadoras de esos desajustes en la crianza. Este trabajo intenta mostrar las transformaciones que han sufrido, en el estilo, desde lo más arcaico hasta lo ultramoderno y en la conformación, desde la clásica hasta las más variadas estructuraciones que hoy conviven socialmente. El recorrido por diversos autores que han propiciado pensar el tema de las violencias nos habilita a esbozar algunas conclusiones sobre sus orígenes, algunas líneas de prevención y una amarga sentencia: la democratización de los vínculos familiares está lejos de ser motor de erradicación de los maltratos hacia la niñez en un mundo donde, además, el horror del incesto mantiene su presencia.

\section{Palabras clave}

familia | niñez | violencias | abusos | ultramoderno

\section{Entidad editora}

RevPsi es una publicación de la

Facultad de Psicología (Universidad

Nacional de La Plata, Argentina)

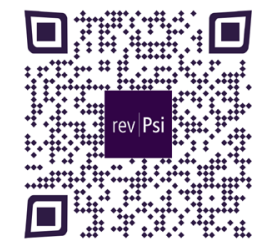

ACCESO ABIERTO DIAMANTE 


\section{0 ultramoderno e 0 arcaico perverso. Persistência do abuso e maus-tratos em organizações familiares.}

\section{Resumo}

Historicamente as organizações familiares estiveram relacionadas com as origens das violências e os abusos sobretudo contra a infância sob o disfarce ou o escudo da educação. Pensou-se que as formas rígidas na estruturação das mesmas seriam em parte facilitadoras destes desajustes na criação. Este trabalho procura mostrar as transformações que a família sofreu, no estilo, desde o mais arcaico até ao ultramoderno, e na conformação, desde a clássica até as mais variadas estruturações que hoje convivem socialmente. O percurso através de vários autores que permitiram pensar sobre a questão das violências habilita a expor algumas conclusões sobre as suas origens, algumas linhas de prevenção e uma amarga sentença: a democratização das relações familiares está longe de ser o motor de erradicação dos maus tratos para com a infância num mundo onde, além disso, o horror do incesto mantém a sua presença.

\section{Palavras-chave}

familia | infancia | violências | abusos | ultramoderno

\section{The ultramodern and the archaic perverse. Persistence of abuse and mistreatment in family organizations}

\section{Abstract}

Historically, family organizations have been related to the genesis of violence and abuses, mainly against childhood under the disguise or shield of education. It has been thought that the rigid ways in the structuration of them partially have been enablers of those childhood issues. This work intends to show the transformations that the family has suffered, in style, from the most archaic to the ultramodern, and in conformation, from the classic to the most varied structures that coexist today in our society. The path through diverse authors who contributed to think about violence has allowed us to outline some conclusions about its origins, some prevention lines and a bitter statement: the democratization of familiar ties is far from being the driving force of eradication of childhood mistreatment in a world where, in addition, the horror of incest maintains its presence.

\section{Keywords}

family | childhood | violence | abuses | ultramodern 


\section{Aspectos destacados del trabajo}

- Se explora el bienestar emocional en madres de niños con TEA, un tópico poco investigado.

- El análisis considera la dimensión Bienestar Emocional del concepto calidad de vida familiar de Turnbull.

- Se incluyen fragmentos de testimonios que son analizados cualitativamente.

- Destaca el lugar que dan las madres a agrupaciones de familiares para afrontar situaciones adversas.

Las nuevas organizaciones familiares no son nuevas; nuevo es el registro de lo que existía, omitido, silenciado o negado. Nuevas son las tecnologías que facilitan la aparición de vinculaciones sociales y familiares y de identidades y subjetividades ligadas a tales tecnologías.

Eva Giberti (2005).

No se puede seguir pensando el maltrato como una herramienta correctiva equivocada pero bien intencionada, ni el abuso sexual infantil como una compulsión sin freno. Ni el maltrato tiene por objeto una niñez sana, ni el abuso responde a una necesidad sexual.

Jorge Garaventa (2005).

Que se haya dicho hasta el hartazgo no nos exime de subrayarlo: las organizaciones familiares resisten el paso del tiempo y prometen larga vida. Han mudado formas y modos, estructuras de presentación y de organización, pero, por lejos, continúan siendo el núcleo social primordial que planta hijas e hijos en la sociedad y determina los formatos del ingreso a la cultura de los mismos. Es un proceso en continua transformación a través de los años, pero, justo es reconocer que en las últimas décadas este se ha revolucionado a sí mismo de forma tal que hoy es complejo determinar cuál es el formato predominante. Más allá de todo, las organizaciones familiares alojan en su seno el ejercicio y aprendizaje de las violencias que luego transitan los distintos estamentos de la sociedad ante la mirada llamativamente ingenua de quienes insisten en no comprender que la familia no necesariamente es el mejor lugar para niñas y niños. Esto no nos impide reflexionar en que cualquier 
cambio que apunte a la erradicación de las preocupantes violencias cotidianas debe incluir un trabajo con ellas.

No se puede pensar la violencia intrafamiliar, que en ocasiones es maltrato hacia la niñez o la mujer, como desgajada de los estímulos sociales, pero tampoco obviar la dinámica intrínseca.

La niñez observa ávidamente los comportamientos adultos e incorpora patrones de conducta y acciones, se identifica y repite. Esto es importante tenerlo en cuenta al momento del abordaje de cuestiones tan preocupantes. Lo social, se ve a diario, transforma las familias y crea modalidades de época, pero el eje de los cambios que permitan avizorar una sociedad diferente debe tener su epicentro en la escuela y la familia. Se habla de una tarea que ha de ser pensada, planificada y ejecutada a través de políticas públicas, cuestión que sostendremos a lo largo de nuestro trabajo.

Louis Althusser (2003) afirmaba que en los años 70 la escuela era unos de los aparatos ideológicos del Estado al servicio de sostener el statu quo funcional a la dominación imperial reinante. Hoy se intenta repensar aquel encapsulamiento ideológico, comprensible en dicha coyuntura. Posicionarse de esta manera habilita a concebir los esquemas familiares como un espacio privilegiado para cuestionar y deconstruir tanto las formas violentas de crianza como las estructuras jerárquicas y los roles estereotipados que concluyen en la naturalización, perpetuamiento, trasmisión y endiosamiento de los estilos violentos de educación y tutelaje.

No debe perderse de vista que, cuando se avanza en un sentido, inmediatamente aparecen los anticuerpos que intentan marcar con tinta roja la supuesta y temida nocividad de los cambios en ciernes. Un ejemplo claro es el cuestionamiento sobre los efectos de la democratización de los roles familiares. Jamás el planteo fue el de borrar las diferencias cuando no está en discusión que un niño o una niña necesitan adultos responsables que acompañen su desarrollo y crecimiento.

Somos, en ese sentido, tributarios de Silvia Bleichmar (2010) y sus impecables desarrollos sobre la crianza. La prolífica psicoanalista, lamentablemente fallecida prematuramente, basaba su esquema en la concatenación de tres conceptos: "amor", "responsabilidad" y "asimetría". No es posible una buena crianza que no se sostenga en el "amor". Si este no está, difícilmente el destino de cualquier niño o niña sea lo más venturoso que se pueda desear. El desamor hace estragos en la mente de niños y niñas y es fundante de los malestares psíquicos y traumas que se transitan durante toda la vida.

En segundo lugar se habla de "responsabilidad". Padres y madres, cualquiera sea la conformación y situación familiar en la que se encuentren, tienen una indelegable responsabilidad por el ser que tutelan. La forma en que va creciendo y se va insertando en la cultura y el mundo exige ese ejercicio parental, que implica postergaciones 
parciales en el acompañamiento, desde la dependencia plena hasta la autonomía, progresiva por largos períodos.

Finalmente hay que hacer referencia a la "asimetría", que es una coordenada esencial en este desarrollo. La lucha contra el modelo padre padrone, el reclamo de la democratización de la familia, no nos excusa de la necesaria diferencia. Adultos, niñas y niños no son lo mismo cuando hablamos de maternidades y paternidades responsables. Pero, además, en estas circunstancias, considerarse pares o amigos no es un valor sino más bien la elusión de responsabilidades en uno de los momentos cruciales en la formación de la psiquis de un ser humano que necesariamente necesita ser tutelado. De ahí al ejercicio autoritario de los roles hay una distancia muy grande que escapa a nuestros razonamientos.

Hanna Segal (1964/1977), en su magnífico desarrollo sobre la obra de Klein, nos ilustra acerca de un aspecto de las conceptualizaciones de la psicoanalista inglesa que enlaza con lo que recientemente describimos y se concatena con lo siguiente. Lo primero que hay que subrayar es que Klein habla de la existencia del "Yo" en una etapa muchísimo más primaria que Sigmund Freud, con una presencia activa y desarrollada ya en los primeros tiempos de vida. Esto le permite pensar en un "Yo" tempranamente dinámico y custodiado por mecanismos de defensa contra ataques fantaseados desde la prolífica actividad psíquica del bebé, según la particular visión de la psicoanalista inglesa. Distingue dos etapas en el desarrollo temprano, las "posiciones" "esquizoparanoide" y "depresiva".

En la primera, el niño experimenta un profundo amor hacia su madre por los estímulos eróticos y positivos, a la vez que un marcado odio cuando padece frustraciones tales como la ausencia temporaria materna, la demora en su alimentación, o la carencia de abrazos en el momento que lo desea. Esta etapa cubriría los primeros 6 meses de vida. Para resguardarse de una experiencia que lo dejaría en la indefensión aparece el mecanismo de splitting, una disociación un poco más intensa (y por momentos hasta múltiple) que divide los objetos en buenos y malos, su madre entre ellos. Klein habla aquí de "pecho bueno" y "pecho malo" (en Segal, 1964/1977).

En la segunda etapa advierte que los estímulos frustrantes y gratificantes provienen del mismo efector, o sea, su madre. La culpa, la reparación y el temor a la retaliación, venganza por parte del objeto atacado, ya están instalados, por lo cual es fundamental la forma en que resuelven los procesos de empatía que a continuación describiremos (Segal, 1964/1977).

De lo anterior subráyese la intensidad de los sentimientos. Se ejemplifica siempre diferenciando la emoción adulta, que atraviesa diversos filtros, de la de los niños, matizando la crudeza que experimentan estos últimos. Cuando ante la frustración de la teta o de un nuevo hermano se desea la muerte del otro, esto en la psiquis embrionaria tiene visos de lo concreto. No hay allí distancia emocional entre la 
fantasía y la realidad. Falavigna (2017) parte del éxito o fracaso del vínculo empático para intentar entender el origen y desarrollo de las violencias, tanto en el seno familiar como en el social. Si bien es un conjunto de ideas que reclaman ser complejizadas, a los fines del presente trabajo son muy ilustrativas.

La empatía es un componente esencial que surge en las primeras etapas de la relación madre- hijo y cuyo devenir puede determinar las formas con las que el individuo se va enlazando con el mundo en el futuro. Se suele hablar de maternaje exitoso o fallido. Es un profundo e intenso sentimiento que permite percibir al otro en su plenitud en un espacio emocional de ida y vuelta. Cuando se crece en un vínculo empático se está transitando el camino que permite reconocerse como personas, individuos. Una madre empática calma enojos y suaviza las ansiedades producto de los sentimientos que describíamos cuando hablábamos de Klein. Esta contención que le provee el vínculo habilita sortear de manera menos traumática los obstáculos que van desde la dependencia absoluta del cachorro humano hasta la independencia adulta.

Desde siempre se relaciona el ejercicio de la empatía con la mirada. Y es justamente esta mirada fundida entre madre e hijo la que actúa de sostén, al estilo del decir de Donald Winnicott (2010) cuando hablaba de lo constituyente que era el holding, el acto de sostener al niño: "sos tenido". Falavigna (2017) concluye en ubicar la génesis de la predisposición del sujeto para las violencias en las brechas empáticas. Dicho en primera persona: si no soy registrado en mi sentir, mi pesar o mi hacer, tampoco lo soy en mi deseo. Si no soy registrado como persona, no hay lugar para mi ser. ¿Cuáles son las potencialidades que emergen, entonces, según este esquema, tal vez un poco rígido y lineal pero útil para entender por qué algunos sujetos sí, y otros no, recalan en las violencias? El deterioro, la falencia o la ausencia de un vínculo empático genera un enojo conductor de pulsiones agresivas que se traducen en ejercicio de la violencia: hacia afuera, donde el individuo sale a matar, hacia dentro como forma de victimización directa como son las conductas suicidas o la secuela de accidentes; en estos casos el sujeto sale a morir; y finalmente esas formas imbricadas como las adicciones donde el sujeto sale a matar o morir. Se constituye como un desarrollo un tanto lineal pero se adopta el esquema para visibilizar cómo se generan ciertas predisposiciones.

Las violencias, según las concepciones a las que se adhiera, son aprendidas y en todo caso lo que aparece como intrapsiquico solo es eficiente en combinación con otras causas. Se postulan las series complementarias que Freud (1916/1993) describió con tanta pertinencia, pero poniendo el énfasis (y más en épocas urticantes) en lo que Luis Hornstein (2018) bautizó como la cuarta instancia freudiana: la realidad externa. Precisamente son varias las corrientes que han intentado poner palabras al origen y los avatares de las violencias dentro de las organizaciones familiares. La explicación es multicausal y difícilmente una sola lectura pueda dar un desarrollo explicativo totalizador. Aquí es necesario el concurso de la interdisciplina ya que 
ninguna línea tiene el saber total sobre los hechos que convocan.

Las corrientes conservadoras suelen referir a esta célula social, la familia, como la garantía de defensa de los valores, los privilegios y las transformaciones tradicionales. Lejos de ello, se postula como la potencial punta de lanza de un cambio disruptivo de lo establecido pasible de ser modificado. Con esfuerzo, esta es la sociedad que se ha logrado. Es necesario pensar en otros modelos donde la paz y la felicidad sean un horizonte posible. ¿Cómo no recordar a Jean Paul Sartre (1943/2016) en su desesperada proclama cuando trataba de sacudir la modorra del escepticismo existencial? Lo importante no es lo que se hace de nosotros, sino lo que hacemos nosotros mismos con lo que se ha hecho de nosotros.

No obstante, no se habla de iniciativas personales ni de grupos con voluntad política más o menos marcada, sino de la imprescindible intervención del Estado a través de políticas públicas. Esta requiere algunas precisiones y un claro posicionamiento ideológico, si se quiere. Desde esta concepción, la idea que se tenga sobre el Estado y la asignación de presupuestos para determinadas cuestiones van de la mano. Por ello se afirma que cuando se habla de falta de presupuesto no se hace referencia a asuntos económicos sino a decisiones políticas acerca de intervenir o abstenerse. Desde el marxismo hasta las corrientes ideológicas más convivenciales, diferentes personas han reflexionado sobre esto arribando a conclusiones respetables pero sectorizadas. Incluso en los últimos tiempos se han peyorizado las intervenciones que tienden a paliar inequidades sociales. Se hace imprescindible entonces trasmitir con claridad de qué se habla cuando se habla de Estado, ya que es el grueso de la sociedad quien tiene que reclamar y validar su presencia activa.

La segunda cuestión a la que necesariamente remite esta reflexión es la ineludible necesidad de hacer una tajante diferencia entre gasto e inversión. El gasto ha de ser racionalmente medido. La inversión busca un beneficio que no forzosamente es económico, pero que hace a un bienestar colectivo inmediato o a largo plazo. El ejemplo más claro es cuando se sostiene que salud y educación no son un gasto sino una inversión ineludible. Invertir en salud y educación asegura ganancias a largo plazo a nivel social, ético y finalmente también económico.

La disputa acerca del tamaño del Estado nos excede y carece de interés para este escrito, pero no nos permite perder de vista que las corrientes liberales economicistas lo conciben en su mínima expresión y confinado a funciones meramente administrativas. El lema con que se martilló a la población durante años fue: "Achicar el Estado es agrandar la Nación". Esa proclama y la consecuente ruptura de los lazos sociales fueron siembras exitosas que aún persisten en la epidermis social ya que, como se comprenderá con facilidad, van de la mano.

Resumiendo: desde la presente concepción los gobiernos han de administrar los bienes del Estado para racionalizar el gasto público sin perder de vista que la función 
indelegable es la intervención en pro de la armonía y la justicia social. El diseño de proyectos, leyes y programas para garantizar derechos no basta si no va acompañado del necesario financiamiento. Y esto no es un desvío retórico. Se sigue hablando de las violencias y sus efectos. Cuando se debate sobre femicidios, violencias contra la mujer, abusos sexuales contra niñas, niños y adolescentes, se suele afirmar que se pueden tener las leyes más avanzadas, que es el caso de la Argentina, pero que estas son letra muerta si no se crean las condiciones para su aplicación. La Ley Nacional de Salud Mental, la de Protección Integral para Prevenir, Sancionar y Erradicar la Violencia Contra las Mujeres en los Ámbitos en que Desarrollen sus Relaciones Interpersonales, y el hecho de que aún no se aplica cabalmente una normativa penal juvenil forman un muestrario irrefutable.

Sigamos con lasfamilias. Se dice, y es fundamental aceptarlo, que no toda organización familiar es reservorio de violencias. La discusión es vana y banal, pero además corre el eje del asunto que (pre)ocupa. Jorge Luis Borges, en un recordado reportaje en el diario La Nación, sostuvo un interesante intercambio acerca de los desaparecidos. "Los familiares -decía Borges- afirman que hay treinta mil desaparecidos" (...) los militares -agregó- dicen que son apenas tres mil (...) En el camino se pierde de vista que con que haya un solo desaparecido ya estamos en presencia de una falla ética gravísima", finalizó. La contundencia de la reflexión pone las cosas en su lugar; la ética por encima de los números.

Entramos, ahora sí, en los procesos de transformación familiar aludidos. Bastante luz nos aporta Élisabeth Roudinesco (2003) cuando alerta acerca de "la familia en desorden" al hacer eje en la urticaria social que significó la decisión de las personas del mismo sexo de buscar amparo legal para sus estructuras hogareñas. Se plantea históricamente un desacuerdo con la psicoanalista francesa que en lo más mínimo lesiona la importancia fundamental de su obra en estas temáticas.

Dice Roudinesco (2003) que los homosexuales, luego de denostar desde siempre la familia tradicional, empiezan a luchar para lograr el ingreso a la misma doblegando su propia apuesta de unión civil, reclamando la habilitación legal del llamado matrimonio igualitario. La afirmación es parcialmente cierta o parcialmente errónea, según se lea. El colectivo homosexual, constituido mayoritariamente por entonces por gays y lesbianas, no había tenido oportunidad de apartarse críticamente de las formas históricas de organización familiar, ya que había sido exonerado de las mismas a raíz de su orientación sexual. Por aquellos tiempos se los llamaba "diferentes", y bien sabido es el destino extraterritorial que se pretende para quienes no pueden o no quieren portar las banderas de la uniformidad.

No el único, pero sí uno de los que abordó el tema del destino diferente con más profundidad y pertinencia, fue Foucault (2000). Se recomienda "Los anormales", porque es un seminario medular desde nuestra mirada, pero el filósofo ha hecho de esa temática una de las razones de su intenso y profundo camino intelectual. Para 
referirse a las aristas más acusadas del tema alude a la creación del monstruo, que sería lo más paradigmático de lo diferente.

Se ha recreado y extendido la concepción foucaultiana acuñando el concepto de "monstruolización", aplicable fundamentalmente a femicidas, abusadores y violadores, pero también a cualquier individuo en conflicto con la ley penal o con las costumbres. La sociedad habla de estos sujetos como monstruos que hay que extirpar de su seno, acorde a las modalidades punitivas de cada época: muerte, confinamiento, cárcel, lapidación, linchamiento. Se decide que son sujetos distintos al conjunto, y que una vez reparada esa falla, o, mejor dicho, puesta la sociedad a salvo de ellos, todo sigue normalmente. Podría ilustrarse con la expresión tan cotidiana y nuestra "aquí no ha pasado nada". No deja de ser una jugarreta consensuada que permite poner el mal afuera. Por ende, como colectivo social perdemos de vista que son producto del funcionamiento de esta misma sociedad.

En realidad, no está en la voluntad social la rehabilitación del sujeto que delinque, y mucho menos la reinserción social. Se lo considera socialmente irrecuperable, tal vez no tanto por reflexión acerca de ello sino porque su presencia desafiando lo establecido actúa como blanqueador de las almas bellas, que así se considera a sí mismo el grueso de la sociedad cuando se confronta con lo diferente. Lejos se está de excusar las responsabilidades individuales en los delitos, y menos aún bregamos por la impunidad. Sostenemos que la necesaria penalización soluciona cuestiones particulares, pero no el fondo de la problemática, ya que quedan intactas las condiciones de producción de dichas subjetividades. En algún lugar de la conciencia social, lo diferente, lo psicopatológico y lo delincuencial se unen en el destino de exclusión que se les supone irremediablemente.

Los avatares en relación a la Ley Nacional de Salud Mental, la n 26657, pusieron en evidencia muchas de las cuestiones que se nos plantean. Lo más revulsivo para quienes se han opuesto y sostienen una encarnizada lucha contra ella es precisamente su concepción inclusiva y la embestida contra el aislamiento social y la estigmatización hacia personas que padecen alguna forma de patología psíquica desde el antiguo posicionamiento psiquiátrico- manicomial, que guió las intervenciones hegemónicas en la materia. Esta ley, de cuyo alcance no se tiene aún conciencia plena, viene a transformar los parámetros de inclusión-exclusión que regían y rigen aún la mayoría de las intervenciones. Tenerlo claro es fundamental cuando estamos internándonos en terrenos que entrelazan las familias, la educación y las violencias.

Como adelanto de las conclusiones, es momento de decir que cuando se valida la "monstruolización” se dejan intactas las condiciones de producción de estos sujetos de violencia y queda impune la responsabilidad social, además de no resolver ni transformar las condiciones sociales de producción de sujetos que se deslizan hacia prácticas de supervivencia en conflicto con la ley penal. La sociedad los genera para eso, y luego intenta extirparlos como si hubieran brotado de una piedra o caído del 
cielo, al decir de Freud.

Previendo el estilo de críticas que suelen circular ante estas reflexiones vamos a subrayar, a riesgo de ser reiterativos. Afirmamos que se está lejos de plantearnos la abolición de las responsabilidades individuales, sobre todo cuando de violencias se trata. Sencillamente queremos alertar que la prevención y erradicación de las mismas reclama otro enfoque más globalizador. Es fundamental intervenir sobre las singularidades, y necesario desde los tres grados de prevención clásicos, pero sin perder de vista que se soluciona esa situación pero el resto sigue intacto.

Podría argumentarse, como un desvío grosero, que hablando de homosexualidad y familias recaemos en temáticas más propias de la psiquiatría y el derecho. La psiquiatrización y la criminalización de las elecciones sexuales diferentes y la impunidad con que se las sostiene nos excusa de mayores explicaciones. El colectivo homosexual ha sido visibilizado como un riesgo para las tradiciones sociales, sobre todo las familiares, y ha padecido todo tipo de violencias por su condición.

Los disfraces de la convivencia suelen ser habitados por una repulsa amable cuando, por ejemplo, se consiente la presencia en guetos que no contaminen demasiado lo establecido.

Ninguna época social puede ser modelo de tolerancia hacia la diferencia, y no es casual que nuestros tiempos de cambios tan sostenidos y revolucionarios sean a su vez escenario de las intolerancias más violentas y extremas.

La globalización informativa ha permitido observar lo que ocurre en distintas sociedades con otras conformaciones y evoluciones pero con una identidad violenta: también enfermos mentales, homosexuales, mujeres y niños son objetivo de todo tipo de crueldades con distintos grados de justificación y naturalización. El reclamo de unión civil en los primeros tiempos y de matrimonio igualitario luego no formaba parte de un deseo colectivo de ingreso al establishment familiar, sino que era parte de una lucha por la visibilización. Se trataba de salir de las zonas de marginalidad y exclusión al que el sistema había condenado y relegado a la población LGBTIQ (lesbianas, gais, bisexuales, trans, intersex y queer), para que se sumaran a la sociedad desde una inclusión igualitaria. No es parte del objetivo del presente trabajo, por eso no se desarrollará este tema, pero tampoco se puede afirmar que la estructura familiar que se buscaba legalizar calcara la tradicional vigente para heterosexuales.

En tiempos de aceleraciones vitales, el libro de Roudinesco (2003), de imprescindible lectura, puede injustamente sospecharse desactualizado cuando en sus páginas transcurren los más contemporáneos debates sobre familia, género y procreación.

El formato familiar tributario del matrimonio igualitario es, al menos por ahora, un punto de llegada con una larga historia de uniones de hecho, de familias 
homoparentales, como se decía en otro momento, que sacudía prejuicios y resistencias sociales, uno de los cuales era precisamente la disolución de la familia como estructura social. Lejos de ello, se increpaba la exclusión y se reivindicaba el derecho universal a constituir familias que también, con la ayuda de las nuevas tecnologías al servicio de la reproducción, o con la ampliación del derecho de adoptar, permitirían ser padres, madres, con elecciones sexuales diversas pero que no necesariamente castraban el derecho y deseo de ser eslabones en la continuidad de la humanidad. La resistencia social al cambio y a lo diferente, el ímpetu de defender el modelo con eje en el padre padrone y en los consagrados valores de la heterosexualidad contundente ponían un nuevo tema en marcha: hijos e hijas criados por lesbianas o gays reproducirían la elección sexual de sus padres-madres.

La respuesta de los grupos incluía una ironía de irrefutable contundencia: la totalidad de los gais y lesbianas conocidos provenían de hogares heterosexuales. Podría pensarse que el colectivo homosexual se hacía cargo del debate intentando mostrar que la homosexualidad no era un riesgo para la paz social. Si la estigmatización de lo diferente estaba en el corazón del debate, no menos riesgoso era para los defensores a ultranza de los valores tradicionales que esos diferentes reclamaran derecho igualitario, y nada menos que para constituirse como estructura familiar.

Si se permite otra digresión, se exponen algunas palabras más sobre el remanido argumento del riesgo de la paternidad/maternidad homosexual en relación a la crianza de niños y niñas. No se necesitan autores contemporáneos, aunque sí vigentes. Freud acuñó conceptos inequívocos sobre la homosexualidad, génesis, desarrollo e inserción social. La carta a la madre del joven homosexual es un escrito fundado y fundante que por razones que ignoramos no ha tenido la importancia que debería en los ámbitos del más allá de lo psi.

Decía Freud en 1935:

La homosexualidad no es, desde luego, una ventaja, pero no hay en ella nada de lo cual avergonzarse: no es un vicio ni un envilecimiento y no podría calificársela de enfermedad; nosotros la consideramos como una variación de la pulsión sexual provocada por una interrupción del desarrollo sexual. Muchos individuos sumamente respetables, de los tiempos antiguos y modernos, fueron homosexuales, y entre ellos encontramos a algunos de los más grandes hombres (Platón, Miguel Ángel, Leonardo Da Vinci). Perseguir la homosexualidad como un crimen es una gran injusticia, y también una crueldad.

Roudinesco (2003) concluye que Freud afirmó que es en vano intentar convertir en homosexual a un heterosexual. De sus escritos se deduce también la inversa. A los fines del escrito, todo el debate en torno al matrimonio igualitario y la unión civil tomó importancia porque iba de la mano del derecho a la adopción. Que 
niñas y niños crecieran en hogares del colectivo LGBTIQ generó debates revulsivos y masivas marchas públicas tanto a favor como en contra de una normativa que finalmente fue aprobada por el Congreso de la Nación Argentina.

Un libro con autores convocados por la CHA (Comunidad Homosexual Argentina) en el que confluyen, entre otros, Eva Giberti, Juan Carlos Volnovich y el autor de esta nota da cuenta de los fundamentos de la necesidad de destrabar el acceso a un hogar de tantas niñas y niños en dilatadísimos procesos de adopción (Giberti, Volnovich y Garaventa, 2004). Los años transcurridos dan cuenta de lo apropiado de la iniciativa. Ninguno de los temidos fantasmas finalmente se corporizó y miles de niños y niñas acarician la felicidad de integrarse en una familia. Pero el árbol no puede ni debe tapar el bosque. Se habla de adopción y de abandono. La mayor parte de los niños que están en situación de abandono son menores abandonados, y muchos de ellos en proceso de judicialización por maltrato. El abandono, la violencia intrafamiliar y el abuso sexual son tres flagelos que castigan a la niñez sin que, por el momento, pueda pensarse que la erradicación esté cercana.

Ningún formato familiar se ha mostrado ajeno al ejercicio de la violencia contra niñas y niños. Aun en las nuevas conformaciones vemos, no sin decepción, que el fenómeno persiste.

Pretendemos no sumarnos al pesimismo de Freud (1932/2001) en su maravilloso intercambio con Albert Einstein, que merece ser leído para entender los fenómenos sociales que nos atraviesan. Se ve allí a un Freud desesperanzado ante la naturaleza humana y las formas de organización social que ella va estableciendo. La innata agresión es difícil de ser doblegada. Pero en las conclusiones exhibe que no quedó preso de su escepticismo. No obstante, más abarcativo y hasta enciclopédico, si se quiere, resultó el libro de Giberti (2005) La familia a pesar de todo, un metódico trabajo acerca de cómo fueron evolucionando en lo social los grupos familiares, cuál era el estado de desarrollo al momento de la publicación y qué devenir se hace presumible. Pero, para terminar de definir el horizonte ideológico y teórico desde el cual se inició, otro escrito se acerca aún más a la orientación desarrollada a lo largo del presente trabajo, Vulnerabilidad, desvalimiento y maltrato infantil en las organizaciones familiares (Giberti, Garaventa y Lamberti, 2005). El haber elegido la vulnerabilidad y el desvalimiento como coordenadas que posicionan a las organizaciones familiares como padecientes y a la par responsables por los sufrimientos de los más débiles pretende desactivar la ilusión que conduce a suponer que, por definición, las familias serían hontanar de paz y fortalecimiento amoroso para sus miembros.

Como se afirma a menudo, las familias no son necesariamente el lugar más seguro para la niñez. Por eso se ha ido mostrando la relación entre las organizaciones familiares, desde la más tradicional hasta la llamada ultramoderna, y los abusos sexuales y maltratos que finalmente recalan en los eslabones más débiles, niñas y 
niños. Se habla de los distintos formatos de las organizaciones familiares presentes en los tiempos que habitamos, pero sin perder de vista que, en plena coincidencia con la afirmación de Giberti en el epígrafe inicial, lo nuevo no son necesariamente las formas sino la visibilización. Los distintos estilos han salido de las catacumbas y se han puesto en foco, lo que innegablemente colaboró a que cada espacio se nutriera, pero, recurriendo a un antiguo decir, poco nuevo bajo el sol hay en este primer avistaje.

A los desarrollos clásicos ya mencionados hemos de agregar un análisis de los aportes de José Antonio Marina habida cuenta que la intención editorial de la que surge este trabajo lo torna imprescindible (Sabas, 2001). Débese a Marina el concepto de ultramodernidad cuya definición ensaya largamente en un diálogo con Sabas (2001):

La ultramodernidad es ante todo una nueva teoría de la inteligencia. ¿Por qué es importante esto? Porque la idea que tengamos de la inteligencia es un componente esencial de nuestra vida. De manera que, por ejemplo, si creemos que la inteligencia es sólo una facultad de conocer, vamos a pensar que la culminación de la inteligencia es la ciencia. Y eso nos ha metido en un callejón sin salida. Ahora por todas partes, en las universidades, en los centros de enseñanza, en los centros de psicología, estamos diciendo que es una demostración más clara de inteligencia resolver ecuaciones diferenciales que organizar una familia feliz. Eso es una insensatez. ¿Qué problema nos interesa más? Ser felices. ¿Cuál tiene mayor dificultad? Conseguir la felicidad, conseguir una estructura afectiva buena a nuestro alrededor. ¿Qué plantea más problemas? La vida de todos los días. ¿Por qué entonces hemos dicho: "la inteligencia es hacer teoría científica"? Lo que dice la ultramodernidad es que la función de la inteligencia es dirigir el comportamiento para salir bien parados de la situación en que estemos. Sea una situación afectiva, familiar, política, económica, también científica si vas a hacer ciencia... Pero tiene que ver con la acción.

Linares (2015) adjudica a Marina el desarrollo de familia ultramoderna. Sin embargo, siendo rigurosos, no es tan así, se trata de un exceso de generosidad, ya que es él quien describe el nuevo modelo mientras que el filósofo acuña la denominación de familia mercurial, la cual sería producto de un cambio sociológico que propicia su aparición. Esas familias con varios padres, hermanos y hermanastros, fruto de divorcios y rupturas y nuevas composiciones de parejas. La definición no es necesariamente equiparable a la de familia ensamblada ya que esta última denota, al menos en su definición de origen, esquemas más simples de organización donde el eje sigue puesto en la heterosexualidad. Quien pretenda profundizar en los estilos familiares y su historia tiene en la bibliografía al pie una guía de inicio. 


\section{Algunas conclusiones finales}

¿El huevo o la gallina? ¿La familia o la sociedad? Estamos en tiempos donde lo unívoco ha dejado de explicar y nos deslizamos a respuestas inclusivas que engloben supuestas polaridades. No es nuevo. Ya se transitó la dialéctica del amo y el esclavo y la circularidad asfixiante entre víctimas y victimarios en las violencias hacia la niñez y la mujer. La familia, para decir algo obvio y consensuado, es el núcleo social y es en su seno donde se generan las subjetividades violentas, pero no podemos soslayar que familia y sociedad se influencian mutuamente y es en esa sinapsis donde debe darse la intervención.

UNICEF (2019) confirma en sus distintas investigaciones que el maltrato hacia la niñez proviene esencialmente de las figuras más significativas del entorno familiar. También, y lo demuestran tanto la clínica como la Justicia, el más concurrente de los delitos sexuales es el paterno-filial, al cual le siguen los perpetrados por figuras en función tutelar como docentes o líderes de distintas instituciones.

Se destaca que el incesto paterno-filial lo realiza quien tiene a su cargo el deber parental, moral, social y económico de tutelar (Giberti, 2005). Agregamos que, en lugar de ello, o además, lo cual es más perverso, abusa de su hijo o hija (Giberti, 2005).

Todas estas violencias no solo no están en retirada, sino que mantienen una tasa de ocurrencia constante. Podría decirse que la visibilización no ha sido suficiente. Se mencionó antes la visión pesimista de Freud, no obstante, la cual en aquel intercambio con Einstein, después de advertir lo intrínseco de la agresividad y su despliegue en determinadas instituciones a las que señalaba como efectoras de violencia, pudo avizorar una salida esperanzada de la mano de la cultura, concepto que prefería al de civilización:

Las modificaciones psíquicas que acompañan el proceso de civilización son evidentes e inequívocas. Consisten en una progresiva desviación de las tendencias instintivas y limitaciones de los estímulos instintivos. Sensaciones que eran voluptuosas para nuestros progenitores se han hecho para nosotros indiferentes o acaso insoportables; no carece de motivos orgánicos el hecho de que nuestras exigencias ideales en materia de ética y de estética hayan cambiado. Entre las características psicológicas de la civilización, dos parecen las más importantes: el reforzamiento del intelecto, que empieza a dominar sobre la vida instintiva, y la introversión de la tendencia a la agresión, con todas sus consecuencias ventajosas y peligrosas.

Para el creador del psicoanálisis, la "sublimación" tiene un papel central en este proceso, ya que permite mutar en fines nobles las pulsiones agresivas de los humanos. El ejemplo más claro que aportó es el de los cirujanos y su forma de trasmutar el 
sadismo, aclarando que no era posible sublimar totalmente el empuje pulsional. A diferencia del estructuralismo que reinterpretó sus escritos, tenía finalmente esperanza en el rol de la cultura.

La convicción, que confluye con la de la mayoría de los expertos, es que la batalla contra las violencias en general, y contra la violencia dirigida a la niñez en particular, ha de tener el epicentro en la educación. No es una conclusión novedosa. Hace generaciones que se viene proponiendo pero aún no se ha encontrado la voluntad política constante en quienes ocasionalmente conducen el Estado. Porque de lo que se trata es de tomar conciencia de que el proceso pasa por que el Estado haga propias las políticas de prevención. La liebre salta y luego se pierde entre los pastizales. De nada sirve correrla luego.

Hay conmoción ante estadísticas contundentes o casos muy mediatizados, pero, mal que nos pese, se trata de una reacción absolutamente lacunar. Y siempre se recala en respuestas punitivistas o de garantía de derechos, aunque, como ya se sabe, puede tenerse las legislaciones más avanzadas, pero si el Estado no garantiza las condiciones de su aplicación estamos claramente en presencia de letra muerta. Sucede que en este tema también es necesario puntualizar la doble moral social y la facilidad en deslizarse hacia el castigo, que no es otra cosa que el fracaso de la intervención adulta en la crianza. Desde DeMause (1994) se sabe de las barbaridades que los adultos cometen contra la niñez. De la misma manera sostenemos que no se trata de una obsesión educativa sino del ejercicio de poder contra el más débil.

Durante años la educación acuñó y valorizó esquemas violentos hoy en retirada. Esa retirada no necesariamente tiene que ver con una toma de conciencia global, sino con el trabajo de los colectivos contra la niñez. Las violencias se retrotrajeron de forma vergonzante al interior de las familias, y se practican en silencio. "Vergonzante" es algo "que se oculta por vergüenza", mientras que «vergonzoso» es algo "que causa vergüenza". Mientras tanto se ha tenido que incorporar en nuestras leyes que golpear a un niño y a una niña es delito, a la vez que se produce horror por la violencia entre pares, como si nada tuviera que ver con nada.

Se necesita educación con perspectiva de género desde las primeras instancias, que deje de producir niñas rosas con vocaciones de princesa y varones celestes que pretendan ejercer los privilegios de sus supuestas superioridades. Se necesita sembrar conciencia de que la paz es un valor, trabajar con las familias entendiendo que ellas son el espejo donde niños y niñas se miran antes de salir al mundo a desarrollar lo aprendido. Se necesita que los niños y las niñas aprendan el valor de la justicia y que la Justicia finalmente aprenda el valor de la niñez. En un mundo que ha consagrado a la seguridad como un valor supremo, la vulnerabilidad de la niñez sigue siendo un tema pendiente. La riqueza social es la ética. La ética tiene que ver con respetar al otro. La mirada condescendiente con la justicia por mano propia nos empobrece. No hace ricos la pedagogía de la violencia. La educación es el oro que puede hacer 
ricos. Es un planteo posible para el cual se necesita decisión política y constancia más allá de los vaivenes políticos. Pero requiere que cada quien se pueda cuestionar su participación en la persistencia de las violencias por acción, omisión o concepción habilitante.

Las familias son víctimas y victimarias de sistemas sociales que, se admita o no, tienen la violencia como valor. Es necesario un proceso de deconstrucción conceptual y metodológico que sobrepase cualquier iniciativa personal o grupal. Se requiere el concurso organizado del Estado. Y desde la salud, la educación y la justicia, la interdisciplina es irremplazable ya que nadie cuenta con el saber absoluto ni las herramientas totales. Si no lo hacemos, no será la patria quien demande, sino esos niños y niñas que ya de adultos encarnarán como valores propios lo que no se supo combatir con políticas e intervenciones sociales. Y, entonces, ya será tarde para lágrimas.

\section{Referencias}

Althusser, L. (2003). Ideología y aparatos ideológicos de estado / Freud y Lacan. Buenos Aires: Nueva Visión.

Bleichmar, S. (2010). Violencia social y violencia escolar (2. ${ }^{\mathrm{a}}$ ed.). Buenos Aires: Noveduc.

deMause, L. (1994). Why cults terrorize and kill children. The Journal of Psychohistory, 21(4), $505-$ 518 .

Falavigna, G. (2017). Apuntes inéditos de clase Diplomatura sobre Prevención y Tratamiento de la Violencia (Universidad Blas Pascal). Universidad Blas Pascal.

Foucault, M. (2000). Los anormales. México, D.F.: Fondo de Cultura Económica.

Freud, S. (1916/1993). Los caminos de la formación del síntoma. En Obras completas (pp. 326-343). Buenos Aires: Amorrortu.

Freud, S. (1932/2001). ¿Por qué la guerra? En Obras completas (pp. 179-198). Buenos Aires: Amorrortu.

Garaventa, J. (2005). Las organizaciones familiares en la producción de sujetos vulnerados y vulnerables. En E. Giberti, J. Garaventa, y S. Lamberti (Eds.), Vulnerabilidad, desvalimiento y maltrato infantil en las organizaciones familiares. Buenos Aires: Noveduc.

Giberti, E. (2005). La familia a pesar de todo. Buenos Aires: Noveduc.
Giberti, E., Garaventa, J. y Lamberti, S. (Eds.). (2005). Vulnerabilidad, desvalimiento y maltrato infantil en las organizaciones familiares. Buenos Aires: Noveduc.

Giberti, E., Volnovich, J. y Garaventa, J. (2004). Adopción, la caída del prejuicio. Buenos Aires: Ediciones del Puerto.

Hornstein, L. (2018). Ser analista hoy. Buenos Aires: Paidós.

Linares, J. L. (2015). Pasos para una terapia familiar ultramoderna. Temas de Psicoanálisis, 10, 1-21.

Roudinesco, E. (2003). La familia en desorden. Buenos Aires: Fondo de Cultura Económica.

Sabas, M. (2001). La ultramodernidad: Un sistema crítico para el humanismo. Entrevista con José Antonio Marina. Ateneo, 11, 22-28.

Sartre, J. P. (1943/2016). El ser y la nada. Madrid: Losada.

Segal, H. (1964/1977). Introducción a la obra de Melanie Klein. Buenos Aires: Paidós.

UNICEF. (2019). UNICEF alertó en el \#8M sobre los derechos de las niñas víctimas de abuso sexual. Recuperado a partir de https://www.unicef.org/ argentina/comunicados-prensa/unicef- $8 \mathrm{M}$ derechos-ninas-victimas-abuso-sexual

Winnicott, D. (1990). Los bebés y sus madres. Buenos Aires: Paidós. 